\title{
Checking the Relationship between Quality of Work Life and Employees Job Satisfaction of Education District 10 of Tehran
}

\author{
Rogheyeh Najafifar ${ }^{1}$ \\ ${ }^{1}$ Department of Management, Electronic Branch, Islamic Azad University, Tehran, Iran \\ Correspondence: Rogheyeh Najafifar, Department of Management, Electronic Branch, Islamic Azad University, \\ Tehran, Iran. E-mail: esfehani.mohamad3@gmail.com
}

Received: June 27, 2016

doi:10.5539/mas.v10n12p82
Accepted: July 12, 2016

Online Published: July 20, 2016

URL: http://dx.doi.org/10.5539/mas.v10n12p82

\begin{abstract}
Considering the fact that in all of the organization including education organization quality of work life today has found a special place, because this reason lack and vacuum of working life quality cause employees have not spirit that they should have to work, and this leads to job satisfaction and ultimately employee productivity reduce and working environment and career seem hollow. So in this research tried to assess the relationship between work life quality and job satisfaction in Education Organization of Tehran. This research was conducted in period is July and August 2015. The research method is descriptive and correlational and the study population included all employees in the Education Organization 10 District of Tehran. The total number is 100 people. That according to Cochran formula was calculated sample size of over 79 people. In this study, for the data analysis, descriptive and inferential statistical methods such as Kolmogorov - Smirnov correlation test was used. The study results showed that 8 independent variable of this research significantly have significant relationship with dependent variable job satisfaction.
\end{abstract}

Keywords: quality of work life, job satisfaction, occupational welfare, education

\section{Introduction}

Quality of work life is a great idea that managers should try to understand it. When it is speaking about on matters relating to the maintenance of employees in an organization, it is essential that various dimensions which creates different complex individual and group needs and desires individual and pay attention to group and individual differences in interpretation of working conditions quality and study humans with all aspects of existence in relation to work and social life. Looking at the man as a system or part of a working system creates the impression that humans can be studied as a mechanical system (Mirsepassi, 2002, p. 305).

(Walton, 1973), defined quality of work life as employees' reaction to the work especially, its necessary consequences in satisfaction of job needs and mental health. Using this definition, quality of work life emphasize on a personal consequences, work experience and how to improve in order to meet the individual needs of humanity. The concept of job satisfaction is an important and valuable subject in organizations, job satisfaction is a feeling that each person has about their jobs, also quality of work life factors can directly affect the employees' job satisfaction, it solves the problem using the quality of working life with regard to its place, meaning and value. Quality of work life factors can cause the organization job satisfaction, (Rokni Nezhad, 2007).

Since in all organizations including education organization quality of work life today found a special place, because of lacking and vacuum of the working life quality led to employees don't have the sprit that need to have in working and this has led to job satisfaction and finally Employee productivity reduce, work environment and employment of people sound hollow, Therefore, the quality of working life can be very helpful in this regard to improve mood, personality and work of people, So in Iran, especially in Tehran Department of Education 1 Province which can enhance people's job satisfaction by quality of working life, it is one of the basic solutions that can be very helpful in this context. Thus in this research we want to examine whether there is any relationship between the quality of work life and job satisfaction of Education District 10 of Tehran or not?

\section{Generalities of Research}

\subsection{The Importance of the Need for Research}

Theoretical Importance: Nowadays, organizations with strategic approach to human resources see it as 
valuable and smart assets and pay more attention to improving the quality of life. Improvement of employees' quality of life requires efforts to develop protectionist policies, management of human resources. Accordingly, the optimal use of human resources depends on human resources and compiling strategies and actions which are done to protect the body, spirit and human dignity of employees. Based on the theory of McClelland (1997), human requirements is learnt and the most important requirement that its satisfaction is in the workplace, plays an important role in job satisfaction, according to Vroom, value, referring to satisfy one's expected level of returns is their job . Managers must same the positive values of rewarding with job good performance. Studies Shepard (1993), which was based on expected theory, shows that dissatisfaction occurs when a person gradually moves from working alone to work in a group. Herzberg's two-factor theory has emphasized on both the members and the organizational context. Thus, according to the quality of working life has not been extensively studied by theorists in this research will therefore be paid to this issue.

The practical importance: Quality of work life is a comprehensive program that increases staff satisfaction. The purpose of most organization is to increase staff satisfaction in all levels and efforts which is done in this means has brought positive results not only in context of job satisfaction but also in In the context of organizational commitment and economic efficiency Actions, including welfare, health, job security, job design, the importance of career development and career advancement, training and development and so on, is considered the same as quality of work life. Improving work life is one of the most important goals of the organization and its employees. In this regard, it is noteworthy that in terms of quality of work life more studies needed to be done because today this issue is a key to the success of any organization.

\section{Theoretical Foundations}

\subsection{Background of the Research}

\subsubsection{Interior Background of the Research}

Hamidian and et al (2013) In a study entitled examining the effect of job satisfaction and quality of work life on productivity Veterinary Medicine graduate student in Mazandaran province, the results show low benefits and not having the chance to work (progress) is considered the most important factors in their productivity. Masumi et al (2013) in a study entitled Examining the relationship between quality of work life and job satisfaction in Mamasani cities offices of education and Rostam, the results show in a significant level of 0,05 that there is a significant positive correlation between quality of work life and job satisfaction in education of Rostam and Mamasani cities. Conclusion improve the quality of work life is one of the most reasonable assumptions subordinates to motivate people and increase job satisfaction.

\subsubsection{External Background of the Research}

Rafael et al. (2013) the research conducted as the relationship between spiritual intelligence and well-being. The research summary was that spiritual intelligence of religious people is much higher than other people. Naeem and Malik (2011) in a study entitled The Role of Spirituality in job satisfaction and organizational commitment of faculty in higher education in Pakistan was done. In this study, we tried to measure whether there is a significant positive relationship between three variables spirituality, job satisfaction and organizational commitment among the three variables among faculty members in public institutions and five private institutions or not?

5 later introduced for the spirituality include self-assessment, organizational character, interactional personality, self-control, transfer mode and self-persuasive that was associated with organizational commitment. To test this this relationship regression tests were used.

\subsection{Theoretical Definitions}

Quality of working life: In a general definition can say that the quality of work life is means mental thought and perception of an organization's staff and their working conditions is desirable physical and psychological work environment (Walton, 1973)

Job satisfaction: It is feeling that people have toward their job, when we say a person have job satisfaction it means that generally he loves his job and it serves a great value and positive emotions towards it (Arnold and Fledman, 1986, citing Shafiabadi).

Life quality: life quality measured by 27 questionaries' which was presented by Valenton (1973).

\subsection{Conceptual Model of the Research}

The research conceptual model is as follows: 


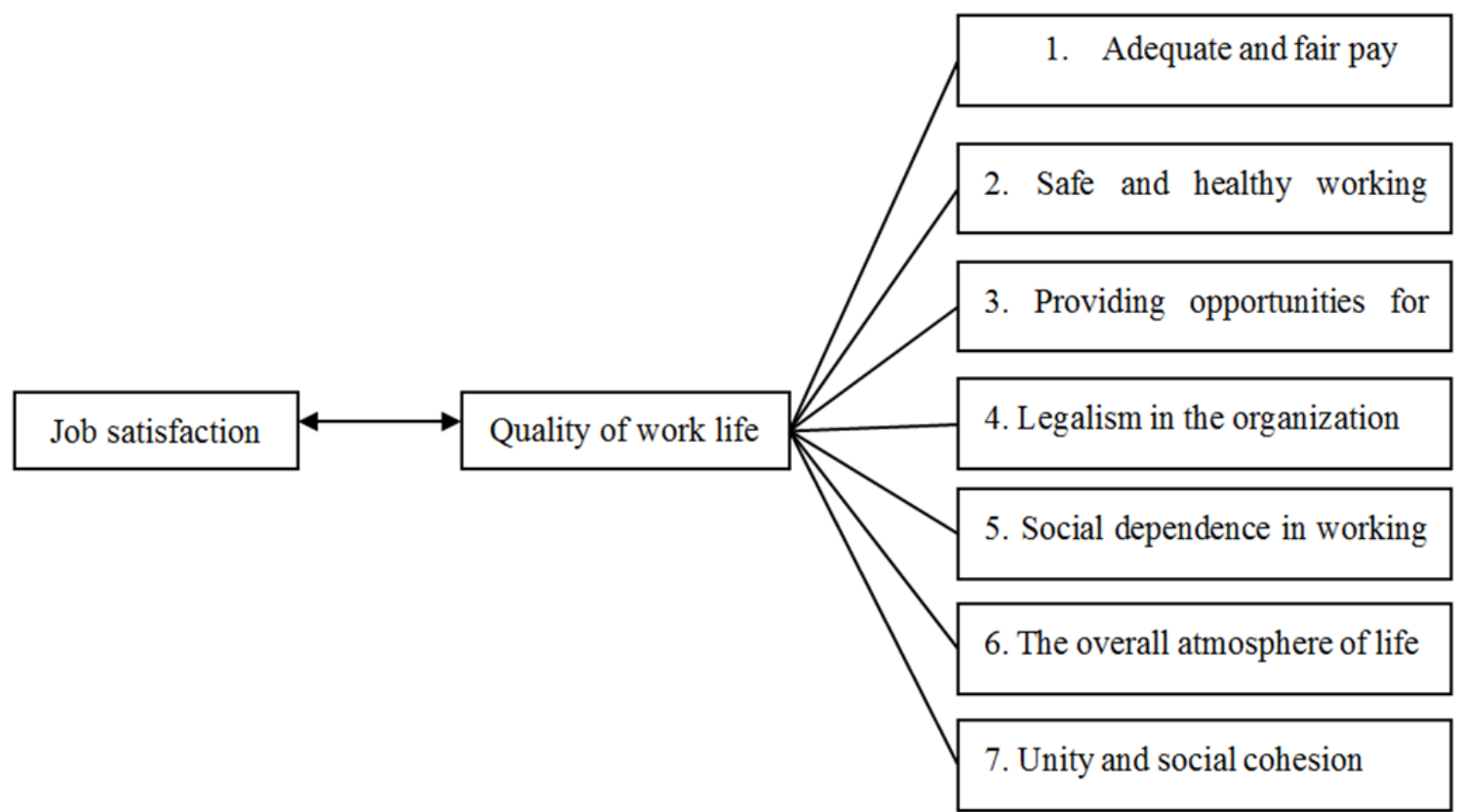

Figure 1. Research (Lee et al., 2015) and (Walton, 1973) and (Smith et al., 1969)

\subsection{Research Hypothesis}

The main hypothesis of research

There is a relationship between Quality of work life and job satisfaction.

Secondary hypotheses

1. There is a relationship between job satisfaction and fair and adequate pay.

2. There is a relationship between the environment health safety and job satisfaction.

3. There is a relationship between constant growth security of supply opportunities and job satisfaction.

4. There is a relationship between Legalism in organization and job satisfaction.

5. There is a relationship between Social dependence and job satisfaction in life.

6. There is a relationship between the general atmosphere of life and job satisfaction.

7. There is a relationship between the unity of social cohesion and job satisfaction.

\section{Methodology}

In general behavioral science research methods can be divided according to two main criteria:

A) The purpose of this study

B) The nature and methodology of research

The present study in term of purpose is functional and in term of data collection method is descriptive and correlational.

\section{Data analysis}

\subsection{Descriptive Statistics Analysis}

Gender: according to the table below 63.5 were male and 35.5 percent of male respondents were women.

Age: $21.8 \%$ of respondents were 30 years and younger, 49.5 percentage were 31-40 year, 19.3 percent were 41-50 and 9.4 percent were 51 and older years.

Education: 10.5 percent of respondents had a high school diploma, $4 \%$ had associate's degree, 49 percent had undergraduate, 32.5 percent had masters, $4 \%$ percent had PHD (Table 3 and Figure 3).

Table1. The distribution of participants by gender, age, education 


\begin{tabular}{llll}
\hline & & frequency & percentage \\
\hline Gender & male & $\mathbf{5 0}$ & $\mathbf{5 . 6 3}$ \\
& female & $\mathbf{2 9}$ & $\mathbf{5 . 3 5}$ \\
& Total & $\mathbf{7 9}$ & $\mathbf{1 0 0}$ \\
\hline Age & 30 years and less & $\mathbf{1 7}$ & $\mathbf{8 . 2 1}$ \\
& 31-40 years & $\mathbf{4 0}$ & $\mathbf{5 . 4 9}$ \\
& 41-50 years & $\mathbf{1 5}$ & $\mathbf{3 . 1 9}$ \\
& 51 years and older & $\mathbf{7}$ & $\mathbf{4 . 9}$ \\
& total & $\mathbf{7 9}$ & $\mathbf{1 0 0}$ \\
\hline Education & Diploma & $\mathbf{8}$ & $\mathbf{5 . 1 0}$ \\
& Associated degree & $\mathbf{3}$ & $\mathbf{4}$ \\
& Bachelor & $\mathbf{3 9}$ & $\mathbf{4 9}$ \\
& Ma & $\mathbf{2 6}$ & $\mathbf{5 . 3 2}$ \\
& PhD & $\mathbf{3}$ & $\mathbf{4}$ \\
\hline & Total & $\mathbf{7 9}$ & $\mathbf{1 0 0}$
\end{tabular}

\subsection{Inferential Statistics}

\subsubsection{Normal Distribution of Variables}

To verify the normal distribution of data Kolmogorov-Smirnov variables test was used. Statistics are as follows.

H0: the data are normal (data come from a normal population)

H1: the data are not normal (the data are not normal population)

If the level of significance test is more than 0.05 , unlike assumption is rejected and it means distribution of variable data is not significantly different from the normal distribution and it can be said normal distribution are entitled.

Table 2. The results of the normality of variables

\begin{tabular}{lll}
\hline Kolmogorov-Smirnov test & & \\
\hline Variables & Statistic Z & Significant level \\
fair and adequate payment & $\mathbf{1 4 8 . 1}$ & $\mathbf{1 4 3 . 0}$ \\
Developing human capabilities & $\mathbf{7 2 5 . 0}$ & $\mathbf{6 7 0 . 0}$ \\
Safe and healthy working environment. & $\mathbf{2 3 8 . 1}$ & $\mathbf{0 9 3 . 0}$ \\
Providing opportunities for growth and continuous security & $\mathbf{7 8 2 . 0}$ & $\mathbf{5 7 5 . 0}$ \\
Legalism in the organization & $\mathbf{6 8 4 . 0}$ & $\mathbf{7 3 7 . 0}$ \\
Social dependence of work life & $\mathbf{7 9 5 . 0}$ & $\mathbf{5 5 2 . 0}$ \\
Integrity & $\mathbf{7 8 1 . 0}$ & $\mathbf{5 7 6 . 0}$ \\
The overall atmosphere of life & $\mathbf{1 1 8 . 1}$ & $\mathbf{1 5 1 . 0}$ \\
\hline
\end{tabular}

\subsubsection{Normality Test (Kolmogorov - Smirnov)}

To assess the normality distribution dependent variable we use this test, if the result shows that the normal distribution of data Pearson correlation test and if shown that it is abnormal nonparametric we use Spearman correlation which is coefficient of Pearson. The results of which are summarized in the following table:

Table 3. Results Kolmogorov-Smirnov test

\begin{tabular}{lll}
\hline The dependent variables & Kolmogorov - Smirnov Z & significant \\
\hline Job satisfaction & 0.897 & 0.397 \\
\hline
\end{tabular}


As it can be seen results for all variables have a significance level of 0.05 . This shows the distribution of these variables is normal and should use Pearson's correlation coefficient.

\subsubsection{Pearson Correlation Coefficient}

This factor is to determine the relationship type and direction of the relationship between two variables or a variable distance or relative distance and a relative variable used. Several equivalent computational methods can define to calculate this coefficient.

A) The calculation method using the raw numbers:

$$
r=\frac{n\left(\sum x y\right)-\left(\sum x\right)\left(\sum y\right)}{\sqrt{\left[n\left(\sum x^{\Gamma}\right)-\left(\sum x\right)^{\Gamma}\right]\left[n\left(\sum y^{\Gamma}\right)-\left(\sum y\right)^{\Gamma}\right]}}
$$

B) The method of calculating the standardized score:

With definition which in it respectively are a standard deviation and variables:

When the correlation coefficient is equal to zero indicates that there is no a linear relationship between two variables.

5.2.4 The Main Hypothesis

$$
\left\{\begin{array}{l}
H_{0}: \rho=0 \\
H_{1}: \rho \neq 0
\end{array}\right.
$$

The hypothesis test showed that the variables of quality of work life and job satisfaction is significant at $1 \%$ level, the hypothesis $\mathrm{H} 0$ is rejected at $1 \%$ existence of correlation is accepted. It is worth mentioning correlation coefficient statistical tests show that the dependent variable (job satisfaction) and independent variable (QWL) have a significant relationship. It is noteworthy that direct relationship between the quality of working life by increasing or decreasing the level of job satisfaction also increases or decreases.

Table 4. Correlation Coefficient quality of work life and job satisfaction

\begin{tabular}{lll}
\hline The dependent variables & Kolmogorov - Smirnov Z & significant \\
\hline Job satisfaction & 0.887 & 0.000 \\
\hline
\end{tabular}

\section{First Sub-Hypothesis:}

Statistical analysis showed that the variables fair and adequate pay and job satisfaction is significant at the $1 \%$ level, the hypothesis $\mathrm{H} 0$ is rejected at $1 \%$ existence of correlation is accepted. It is worth mentioning correlation coefficient statistical tests show that the dependent variable (job satisfaction) with and independent variable (pay fair and adequate) have a significant relationship. It is noteworthy that this coloration is direct it means that with increasing or decreasing the fair and adequate pay levels job satisfaction also increases or decreases.

$$
\left\{\begin{array}{l}
H_{0}: \rho=0 \\
H_{1}: \rho \neq 0
\end{array}\right.
$$

\section{Second Sub-Hypothesis:}

$$
\left\{\begin{array}{l}
H_{0}: \rho=0 \\
H_{1}: \rho \neq 0
\end{array}\right.
$$

Statistical analysis showed that the variables of work environment health and safety and job satisfaction is significant at the $1 \%$ level, the hypothesis $\mathrm{H} 0$ is rejected at $1 \%$ existence of correlation is accepted. It is worth mentioning correlation coefficient statistical tests show that the dependent variable (job satisfaction) with and independent variable (the workplace safety and health) have a significant relationship. It is worth mentioning this coloration is direct it means that by increasing or decreasing the level of safe and healthy working environment job satisfaction also increases or decreases. 


\section{Third Sub-Hypothesis:}

$$
\left\{\begin{array}{l}
H_{0}: \rho=0 \\
H_{1}: \rho \neq 0
\end{array}\right.
$$

Statistical analysis showed that the variables of propriety and job satisfaction is significant at $1 \%$ level, the hypothesis $\mathrm{H} 0$ is rejected at $1 \%$ existence of correlation is accepted. It is worth mentioning correlation coefficient statistical tests show that the dependent variable (job satisfaction) independent model variables (propriety) have a significant relationship. It is worth mentioning this is the direct relationship it means that increase or decrease the amount of propriety increase or decrease the level of job satisfaction.

\section{Forth Sub-Hypothesis:}

$$
\left\{\begin{array}{l}
H_{0}: \rho=0 \\
H_{1}: \rho \neq 0
\end{array}\right.
$$

Statistical analysis showed that the variables provide growth opportunities and continuous security and job satisfaction is significant at the $1 \%$ level, the hypothesis $\mathrm{H} 0$ is rejected at $1 \%$ existence of correlation is accepted. It is worth mentioning correlation coefficient statistical tests show that the dependent variable (job satisfaction) and independent model variable (providing growth opportunities and continuous security) have a significant relationship. It is noteworthy that it is direct relationship means that with increase or decrease the level of providing opportunities for growth and continuous security the level of job satisfaction also increases or decreases.

\section{Fifth Sub-Hypothesis:}

$$
\left\{\begin{array}{l}
H_{0}: \rho=0 \\
H_{1}: \rho \neq 0
\end{array}\right.
$$

Statistical analysis showed that organizational legality and job satisfaction variables are significant at $1 \%$ level, the hypothesis $\mathrm{H} 0$ is rejected at $1 \%$ existence of correlation is accepted. It is worth mentioning correlation coefficient statistical tests show that the dependent variable (job satisfaction) and independent model variable (legalism in the organization) have a significant relationship. It is worth mentioning this relationship is direct means by increasing or decreasing the amount of legality the level of job satisfaction also increases or decreases.

\section{Sixth Sub-Hypothesis:}

$$
\left\{\begin{array}{l}
H_{0}: \rho=0 \\
H_{1}: \rho \neq 0
\end{array}\right.
$$

Statistical analysis showed that the variables of social dependence of work life and job satisfaction is significant at the $1 \%$ level, the hypothesis $\mathrm{H} 0$ is rejected at $1 \%$ existence of correlation is accepted. It is worth mentioning correlation coefficient statistical tests show that the dependent variable (job satisfaction) and independent model variable (social dependence of work life) have a significant relationship. It is noteworthy that this relationship is direct means with increasing or decreasing the amount of social dependence of work life the level of job satisfaction also increases or decreases.

\section{Seventh Sub-Hypothesis:}

$$
\left\{\begin{array}{l}
H_{0}: \rho=0 \\
H_{1}: \rho \neq 0
\end{array}\right.
$$

Statistical analysis showed that the variables of propriety and job satisfaction is significant at $1 \%$ level, the hypothesis $\mathrm{H} 0$ is rejected at $1 \%$ existence of correlation is accepted. It is worth mentioning correlation coefficient statistical tests show that the dependent variable (job satisfaction) and independent model variable (integrity) have a significant relationship. It is noteworthy that this relationship is direct means with increasing or decreasing the amount of integrity the level of job satisfaction also increases or decreases. 


\section{Eighth Sub-Hypothesis:}

Statistical analysis shows that the overall atmosphere of life and job satisfaction variables are significant at $1 \%$ level, the hypothesis $\mathrm{H} 0$ is rejected at $1 \%$ existence of correlation is accepted. It is worth mentioning correlation coefficient statistical tests show that the dependent variable (job satisfaction) and independent model variable (overall living space) have a significant relationship. It is noteworthy that this relationship is direct means with increasing or decreasing the amount of overall living space the level of job satisfaction also increase or decrease.

\begin{tabular}{llll}
\hline Sub-hypothesis & Variable & $\begin{array}{l}\text { The test } \\
\text { statistic }(\rho)\end{array}$ & $\begin{array}{l}\text { Significant } \\
\text { level }\end{array}$ \\
\hline First & & $\mathbf{7 3 4 . 0}$ & $\mathbf{0 0 0 . 0}$ \\
second & The fair and adequate pay- job satisfaction & $\mathbf{6 5 7 . 0}$ & $\mathbf{0 0 0 . 0}$ \\
third & Safe and healthy working environment - Job satisfaction & $\mathbf{7 3 0 . 0}$ & $\mathbf{0 0 0 . 0}$ \\
forth & propriety - job satisfaction & & $\mathbf{0 0 0 . 0}$ \\
& Providing opportunities for growth and continuous security & $\mathbf{7 1 6 . 0}$ & \\
fifth & job satisfaction & $\mathbf{7 8 9 . 0}$ & $\mathbf{0 0 0 . 0}$ \\
sixth & Organizational legality - job satisfaction & $\mathbf{5 4 5 . 0}$ & $\mathbf{0 0 0 . 0}$ \\
Seventh & Social dependence of work life - job satisfaction & $\mathbf{7 4 1 . 0}$ & $\mathbf{0 0 0 . 0}$ \\
eighth & Integrity - job satisfaction & $\mathbf{5 9 6 . 0}$ & $\mathbf{0 0 0 . 0}$ \\
\hline
\end{tabular}

\section{Conclusion}

Various researchers relatively have noted high personal and organizational consequences for the quality of working life. Communication, cooperation and mutual assistance in employees' increases reduces rate errors and promotes participation and involvement of employees in organizations and generally provides a good organizational atmosphere.

Ability of organization sustainability in competitive environment variable of today requires using the quality of working life in the organization. Quality of working life in the new organization is strong enough that many theorists, Managers and decision-makers with adopting the strategy in this respect offer future orientated for organizations. Important part of the organization that would be affected by this issue is the human resources of organization. The organizational changes should focus on manpower demands and variable resolutions and changing customer wishes knowledgeable and pay attention to astute. Most likely from traditional and hierarchical organizations that manage them and follow the reliance culture has no place in this New Age. Naturally how to manage the forces that work in the new environment mean the environment that combines with quality of life will be overwhelmed with this area. If the attitudes of managers and experts are correct, it is possible that in the culture and perspectives of the enterprise, to create fundamental change. In this regard, you can take advantage of tools such as quality of work life and create fundamental changes systematic structure. Organizations that fail in this transformation efforts lose opportunities of living. With using quality of working life in the organization: 1. Better use of the labor force is associated with reduced number of employees and increases the efficiency of individual employees 2. Better use of time for greater efficiency 3. Better quality management with better decision making 4 . Increasing the efficiency with better job satisfaction of people in the organization can be viewed.

\section{Suggestions}

\section{Suggestions based on First hypothesis:}

Create a balance between the salary of the employees with the criteria of a normal lifeand receive salaries on time and fit between salary and working hours can be increased job satisfaction among employees. On the other hand, must identify factors related to fair pay among staff to increase a fairness sense of pay among employees.

\section{Suggestions based on second hypothesis:}

The hygiene principles and safety principles create an environment where employees feel peace in it, and to achieve to this concept that human working conditions designed based on ergonomic principles and they are effective in creating job satisfaction and improvement.

\section{Suggestions based on third hypothesis:}

With the development of human capabilities and create a learning environment for staff and solutions about increasing required skills to create job satisfaction among employees and it is helpful in its improvement.

\section{Suggestions based on forth hypothesis:}


It is necessary about the job security skills required of employees done appropriate act measures to create job satisfaction and it is effective among employees its improvement. Therefore, it is suggested that managers provide potential for growth staff development as well as provide self-management fields. The nature of the job should be such that people can use their learned skills (both before and after entering the organization to organization) in their jobs, that this creating optional creation in a job and giving the power to make decisions to more people will be possible.

\section{Suggestions based on fifth hypothesis:}

It is recommended that organizations put development opportunities and providing ongoing in-service training programs that done periodically according to needs and environmental changes to increase the sense of confidence that it will lead to making more job satisfaction in employee. Also organization must with providing relevant and updated information available to employees, As well as challenging things when designing corporate jobs increases Attractiveness of job, and this way can increase job satisfaction among employees.

\section{Suggestions based on sixth hypothesis:}

It is suggested that managers by holding training courses and promoting corporate culture strengthen the rule of law in the pay of employees in the organization. Also, they themselves with respecting organizational to rules must also strengthen Legalism in the organization, as well as the issuance of the letters and explaining necessary knowledge of employees with organizational rules to ensure staff awareness of the rules.

\section{Suggestions based on seventh hypothesis:}

It is suggested that with the design of organizational jobs so that employees can play their roles in other social responsibilities. Also, it is important to note that organizational goals in line with social goals and employee be sensitive toward maintain environment and feel responsibility toward it and consider organizational goal in line with community excellence.

\section{Suggestions based on eighth hypothesis:}

This is suggest that organization provide working environment in way that employees in organization that it leads to organizational support of the organization's staff and comment without fear of superiors. As well as with dynamic programming and asking a question from themselves for planning the job try to create a balance between personal life and work life.

\section{References}

Hamidian, M., Hamidian, S. N., \& Hojjat, A. (2013). Evaluation the effect on of job satisfaction on quality of work life on productivity of graduate student in Veterinary Medicine. Mazandaran Province, the National Conference of modern management science, Gorgan, non-profit institution of higher education Jorjani

Jeny, R., \& Varghese, P. (2013). Spiritual Correlates Of Psychological Well - Being. Indian Streams Research Journal, 3(7).

Masoumi, L., \& Sohrabi, M. (2013). Examining the relationship between quality of work life and job satisfaction mamasani county offices of education Rustam. The second International Conference on Management, Entrepreneurship and Economic Development, Qom, PNU

Mir, S. N. (2002). Strategic Human Resource Management and Labor Relations. Tehran: Mir puplication.

Muhammad, E. M., \& Basharat, N. (2011). Role of spirituality in job satisfaction and organizational commitment among faculty of institutes of higher learning in Pakistan. African Journal of Business Management, 5(4), 1236-1244,

Rokninezhad, M. (2007). New theories and models of organizational commitment.

Saruqi, S. (2009). Evaluation the relationship between spiritual intelligence and organizational commitment Razavi Khorasan Gas Company. MSc thesis, Islamic Azad University, Mashhad.

Walton, R. F. (1973). Quality of Work life: What is it, Sloan Management Review, fall.

\section{Copyrights}

Copyright for this article is retained by the author(s), with first publication rights granted to the journal.

This is an open-access article distributed under the terms and conditions of the Creative Commons Attribution license (http://creativecommons.org/licenses/by/3.0/). 